\title{
Review of posttraumatic stress disorder and chronic pain: The path to integrated care
}

\author{
Carri-Ann Gibson, MD, DAAPM \\ Mental Health and Behavioral Sciences Service, James A. Haley Veterans' Hospital, Tampa, FL; Morsani College of \\ Medicine, University of South Florida, Tampa, FL
}

\begin{abstract}
With the large number of Veterans experiencing posttraumatic stress disorder (PTSD) and chronic pain, the purpose of this article is to review the prevalence of PTSD and chronic pain, the theoretical models that explain the maintenance of both conditions, and the challenges faced by providers and families who care for these patients. The Department of Veterans Affairs (VA)/Department of Defense (DOD) VA/DOD Clinical Practice Guideline for Management of Post-Traumatic Stress with special attention to chronic pain is presented. Limited scientific evidence supports specific care and treatment of PTSD and chronic pain, and this challenges providers to investigate and research potential treatment options. Integrated care models designed for working with these patients are reviewed, including a focus on the techniques and strategies to address not only PTSD and chronic pain, but other conditions, including substance dependence and depression. A specific focus on headaches, back pain, and neuropathic pain follows, including treatment recommendations such as pharmacological, psychotherapeutic, and complementary approaches, given the high rates of these pain complaints for Veterans in PTSD clinical programs. Integrated care is presented as a viable solution and approach that challenges clinicians and researchers to develop innovative, scientifically based therapeutics and treatments to enhance the recovery and quality of life for Veterans with PTSD and chronic pain.
\end{abstract}

Key words: behavioral activation, blast injury, buprenorphine, chronic pain, comorbid illness, integrated care, opioid dependence, posttraumatic stress disorder, rehabilitation, Veteran.

\section{INTRODUCTION}

As of November 17, 2011, 6,320 U.S. servicemembers have been killed in Afghanistan (Operation Enduring Freedom [OEF]) and Iraq (Operation Iraqi Freedom [OIF]) [1]. An estimated 50,000 to 100,000 servicemembers have experienced nonmortal wounds and injuries during military deployments in OIF/OEF. The number of those injured is staggering, with an unprecedented number of injured U.S. servicemembers returning home compared with previous historical military actions.

Abbreviations: $\mathrm{BA}=$ behavioral activation, $\mathrm{BF}=$ biofeedback, $\mathrm{BOTOX}=$ onabotulinumtoxin $\mathrm{A}, \mathrm{CAM}=$ complementary and alternative medicine, $\mathrm{CBT}=$ cognitive behavioral therapy, $\mathrm{CPT}=$ cognitive processing therapy, DOD = Department of Defense, FDA $=$ Food and Drug Administration, NSAID = nonsteroidal anti-inflammatory drug, OEF = Operation Enduring Freedom, OIF $=$ Operation Iraqi Freedom, $\mathrm{PE}=$ prolonged exposure, PGW $=$ Persian Gulf war, PTSD = posttraumatic stress disorder, RCT $=$ randomized clinical trial, SNRI = serotonin-norepinephrin reuptake inhibitor, SSRI = selective serotonin reuptake inhibitor, TCA = tricyclic antidepressant, VA = Department of Veterans Affairs, VHA = Veterans Health Administration.

Address all correspondence to Carri-Ann Gibson, MD, DAAPM; 13000 Bruce B. Downs Blvd (116A), Tampa, FL 33612; 813-631-7135, ext 4318.

Email: carri-ann.gibson1@va.gov

http://dx.doi.org/10.1682/JRRD.2011.09.0158 
OIF/OEF have resulted in the highest wounded to fatality ratio compared with past conflicts involving U.S. servicemembers. The wounded to fatality ratio for our current military actions is 16 servicemembers wounded per every fatality. During World War I and World War II, there were two servicemembers wounded per every fatality. For the conflicts in Korea and Vietnam, the wounded to fatality ratio was close to three wounded per every fatality [2]. Our nation's wars prior to OIF/OEF resulted in a far greater loss of American lives, with not only fewer servicemembers surviving war injuries, but also a greater number being called to serve in combat.

With a significantly greater number of servicemembers surviving devastating combat injuries today, it is clear that much credit is due to the incredible advances in military medicine. More servicemembers are surviving major combat injuries with the resulting medical, psychological, and social costs to servicemembers, their families, and the Department of Defense (DOD) and Department of Veterans Affairs (VA) medical systems to provide care for those with combat-related injuries. This has resulted in the emergence of multimodal pain management with the identification of proactive, not reactive, pain management to contribute to early rehabilitation and recovery [3]. These Veterans and servicemembers require complex medical care and our medical systems are constantly challenged to address their physical as well as psychological injuries, such as posttraumatic stress disorder (PTSD), as Veterans take steps forward in their lives following military discharge.

In response to the comorbid presentations of both PTSD and chronic pain, the VA/DOD Clinical Practice Guideline for Management of Post-Traumatic Stress was revised in 2010 with a special section devoted to the management and treatment of pain in patients who have PTSD. This article will highlight the clinical practice guideline with the primary purpose of helping clinicians gain a deeper understanding of these conditions as we continue to or begin to develop models of care to best meet the treatment needs of these patients. We must work in collaboration to integrate the care provided in our medical centers for all Veterans with both PTSD and chronic pain.

\section{METHODS}

A search of Medline (Medical Literature Analysis and Retrieval System Online), CINAHL (Cumulative Index to
Nursing and Allied Health Literature), AMED (Allied and Complementary Medicine Database), and PsycINFO (Psychological Information Database) was performed. No start date limit on the search criteria of the databases was set, but the end date was the first week of August 2011.

The search was performed using the following combinations of terms:

- "PTSD and Chronic Pain" within title and abstract.

- "Posttraumatic Stress Disorder and Chronic Pain” within title and abstract.

- "(Posttraumatic Stress Disorder or Chronic Pain) AND therapy” within title and abstract.

- "(Posttraumatic Stress Disorder or Chronic Pain) AND medications" within title and abstract.

- "(Posttraumatic Stress Disorder or Chronic Pain) AND depression.”

- “(PTSD or Chronic Pain)) and Substance Abuse” within title and abstract.

- "Chronic Pain and Opioids" within title and abstract.

- "Chronic Pain and Buprenorphine” within title and abstract.

- "Chronic Pain and Headaches" within title and abstract.

- "Chronic Pain and Neuropathic Pain" within title and abstract.

- “Chronic Pain and Back Pain” within title and abstract.

- "PTSD and Headaches" within title and abstract.

- "PTSD and Neuropathic Pain" within title and abstract.

- "PTSD and Back Pain” within title and abstract.

- "Integrated Care" within title and abstract.

The reviewer independently read the titles and abstracts of the studies found in the search and compiled them for the purpose of this comprehensive review article. Study participants were adult patients with PTSD and/or chronic pain. There are limited randomized controlled trials on both PTSD and chronic pain, so this could not be a primary inclusion criteria. All articles were published in a peerreviewed journal.

\section{RESULTS}

\section{Chronic Pain}

Returning servicemembers experience various forms of chronic pain, including, but not limited to, soft tissue injuries and musculoskeletal pain; neuropathic pain; pain related to severe burn injuries and/or grafts; pain caused by imbedded shrapnel or metal or bone fragments; pain 
related to amputation and/or phantom limb pain; pain secondary to surgeries; and pain related to compression fractures or injuries from falls, jumps, or other types of impact. Many of the aforementioned pain conditions are a direct result of military service and injuries incurred during service. We must also be aware of the high frequency of chronic daily headaches, tension headaches, migraine headaches, chronic lower-back pain, fibromyalgia, and other pain disorders that may not necessarily be a direct effect of military service or injury during service.

It is well known that chronic pain can lead to the development of intense psychological distress, suffering, and functional disability. Pain is described as an unpleasant sensory and emotional experience that is associated with actual or potential tissue damage [4]. Typically, pain is a temporary experience; for some, pain may persist to the point that it contributes to affective distress, increased use of medical services, and workplace absenteeism, with resultant impairment in social and occupational functioning [5-7]. Pain is the most common complaint made by patients to their primary care providers, with an estimated $\$ 75$ to $\$ 100$ billion a year in the United States in lost productivity and healthcare costs; the burden of chronic pain on the individual, families, and medical system of care is significant [8]. It is also well know that there is a high propensity for the development of long-term mental health and substance abuse disorders in those suffering from chronic pain. Chronic pain has been recognized as the leading cause of short- and long-term disability among military personnel, thereby prompting the DOD and VA to look at the clinical programs and services currently available and to promote further research and attention to chronic pain and its related comorbid disorders.

\section{PTSD}

The prevalence rates of PTSD in the general population are found to be 6 percent in males and 12 percent in females [9]. Most people are resilient and can absorb the effect of a traumatic experience and resume their normal lives. Estimates reveal that exposure to traumatic events for those living in the United States are thought to be close to 70 percent [10-11]. Although most people are resilient, a sizeable number cannot absorb the effect of traumatic events and develop PTSD. At-risk groups include those involved in motor vehicle accidents, sexual assault, or military combat, with the rates of PTSD found to be substantially higher than the general civilian population. Dohrenwend et al. reported that 18.7 percent of Vietnam war Veterans had developed war-related PTSD during their lifetimes and 9.1 percent continued to experience PTSD 11 to 12 years after the war following a review of military records to construct a new combat exposure measure [12]. Richardson et al. examined prevalence estimates of combat-related PTSD in U.S. military Veterans since the Vietnam war and found that 2 to 17 percent of Vietnam war Veterans had PTSD. Studies from OIF/OEF suggest that combat-related PTSD affects between 4 and 17 percent of U.S. OIF Veterans [13]. The rates are believed to be closer to 50 percent with those Veterans who have served multiple deployments and will increase with the number of firefights engaged.

\section{Intersection of PTSD and Pain}

Complaints of pain are commonly reported in patients who have PTSD, regardless of the traumatic experience such as military combat, motor vehicle accident, or sexual assault. The reporting of pain symptoms with functional impairment is also independent of the military service period and is seen across the board for World War II, Korean war, Vietnam war, Persian Gulf war (PGW), and OIF/OEF Veterans [14-19]. Among adult survivors of physical, psychological, or sexual abuse, the most common types of chronic pain include pelvic pain, lower-back pain, facial pain, and bladder pain, along with a high prevalence of fibromyalgia [20-21]. In OIF/OEF over the past 10 years, there has been increased interest in the relationship between PTSD and chronic pain.

The Veterans Health Administration (VHA) Office of Public Health and Environmental Hazards reported in April 2011 that mental disorders occur at a frequency of 50.7 percent for servicemembers returning from OIF/ OEF and that diseases of the musculoskeletal system occur at a frequency of 54.7 percent for those who have served in OEF and/or OIF [22]. Patients with persistent chronic pain associated with musculoskeletal injury or serious burn injuries frequently experience PTSD. The National Co-Morbidity Study found that patients with musculoskeletal pain are four times more likely to develop PTSD than those without musculoskeletal pain [9]. Head, neck, back, shoulder, and knee pain have been found to be the most common pain complaints for those who served during OIF/OEF [19].

Clinical and military registries have found pain symptoms and diagnoses to be among the most prevalent conditions reported for PGW Veterans since the cease-fire in 1991. DOD and VA PGW registries' most frequently 
diagnosed medical conditions include musculoskeletal pain at rates of 25 percent and connective tissue diseases at rates of 36 percent. A survey of 15,000 PGW Veterans found prevalence rates for headaches at 54 percent, joint pain at 45 percent, back pain at 44 percent, muscle pain at 33 percent, and abdominal pain at 23 percent [23-25]. Combat Veterans have high rates of pain that also occur with comorbid disorders and are often associated with worse outcomes.

The rates of PTSD when pain is secondary to a motor vehicle accident range from 30 to 50 percent. Burn patients have high rates of PTSD that are close to 45 percent. For those servicemembers currently deployed to OIF/OEF, exposure to improvised explosive devices, other blast mechanisms, and refueling accidents has been found to increase the rates of burn injuries that are then associated with later development of PTSD. Those with PTSD report more intense pain and affective distress, higher levels of life interference, and greater disability than pain patients without PTSD. It has also been noted that re-experiencing symptoms were also associated with increased pain level and pain-related disability [26-27]. For those individuals who have both PTSD and chronic pain, the presence of both disorders may increase the severity and individual suffering from either condition.

PTSD symptoms are also associated with greater reporting of physical health problems and symptoms. Of outpatient Vietnam war combat Veterans with PTSD, 80 percent satisfied the criteria for chronic pain in one or more sites, with 77 percent reporting back pain. It was also found that increased re-experiencing symptoms were connected to an increased pain level and associated painrelated disability [16]. Pain threshold and tolerance are affected by elevations in anxiety, such as that seen in individuals with PTSD. PTSD may reduce pain threshold and pain tolerance, thereby influencing emotional distress and increasing perceived disability levels.

Similar to the presentation of pain symptoms for Vietnam war combat Veterans with PTSD, it is also known that a substantial number of returning Veterans experience ongoing or new pain postdeployment. According to a recent study, OIF Veterans report pain conditions more frequently than other medical conditions, with 47 percent reporting some level of current pain. Of OIF Veterans, 28 percent reported pain scores that were associated with functional interference and scores that were at the threshold for intervention, with a pain score $\geq 4$ on the numeric pain scale [28].

\section{Theoretical Models of PTSD and Chronic Pain}

Four theoretical models have been proposed to outline the connections between PTSD and chronic pain. These include the Shared Vulnerability model, the Mutual Maintenance model, the Fear-Avoidance model, and the Triple Vulnerability model. These models have yet to be formally tested; however, the models can provide more understanding of the symptom overlap between both PTSD and chronic pain, which can prove to be useful on a clinical basis.

The Shared Vulnerability model outlines anxiety sensitivity as a predisposing factor contributing to the development of both conditions. Those with increased levels of anxiety sensitivity are more likely to become fearful in response to bodily sensations such as pain or following exposure to a traumatic stressor. It is proposed that anxiety sensitivity can be a factor that makes an individual vulnerable to the development and maintenance of chronic pain and PTSD by driving avoidance behaviors associated with both conditions [29].

The Mutual Maintenance model describes seven specific components that play a role in the chronic maintenance of PTSD and pain:

1. Anxiety sensitivity with the tendency to view events or outcomes as potentially tragic.

2. Physical pain as a reminder of the traumatic event.

3. Attentional biases that increase awareness and vigilance to perceived threatening or painful circumstances.

4. Avoidance as a means to cope with disturbing thoughts and pain.

5. Elements of fatigue and lethargy that drive depression associated with both conditions.

6. General fears and worries common to both disorders.

7. Overwhelming cognitive demands of both disorders that limit the use of learned coping techniques [30].

It is believed that these components primarily drive the maintenance and chronic nature of both illnesses and ultimately interfere with individuals engaging in treatment.

The Fear-Avoidance model describes the role of avoidance in the maintenance and development of both PTSD and chronic pain. Individuals with PTSD are driven by the fear of experiencing overwhelming thoughts or feelings of past traumatic events and avoid reminders associated with the traumatic event at all costs. This fear and avoidance contributes to the chronic nature of the illness through the prevention of processing of the traumatic event. Without processing the traumatic event, individuals 
with PTSD are propelled to isolate and avoid potentially traumatic reminders [31-32].

Finally, the Triple Vulnerability model of anxiety and PTSD outlines a set of vulnerabilities that must be present to develop an anxiety disorder, such as a generalized biological vulnerability, a generalized psychological vulnerability, and a specific psychological vulnerability where one focuses anxiety on specific situations. With PTSD, emotional reactions to events emerge in an unpredictable and uncontrollable way. With chronic pain, when one perceives her or her pain as uncontrollable, this drives an individual's sense of low self-efficacy and depression. At this point, individuals will avoid situations in which pain may occur, as also seen in PTSD. The alarm of a trauma reminder or pain reminder, along with the sense of uncontrollability, is believed to foreshadow the establishment of both illnesses [33-34].

With further examination and translation to clinical work with former combat Veterans, it is my opinion that the Mutual Maintenance model appears to be the theoretical model that is commonly seen in Veterans with both PTSD and chronic pain. Both illnesses seem to drive the challenges that many Veterans and their loved ones face as they struggle to re-engage in their lives outside of their combat traumas and military experience. Many Veterans with both disorders will say that, prior to the development of PTSD and chronic pain, they were very active with their families and friends. For many, this involved playing sports, going to the park with their kids, exercising on a regular basis, and attending sporting events with their friends. With both disorders, Veterans share a profound struggle with resistance to engaging in physical activity because of the possibility of exacerbating their chronic pain and avoidance of going to the park or other public places because of their anxiety and emotional distress when in a crowded place. This leads to a cycle of guilt, shame, and regret, in that many Veterans will say they wish they could be at the park or the sporting event or with their families. They also say that they miss the physical aspects of their lives prior to combat, but with their avoidance symptoms, they find an enduring sense of safety and relief when they remain at home. This is the cycle of PTSD and pain that is maintained and challenges us as clinicians when we provide treatment for our patients.

Avoidance is believed to prevent habituation to trauma-related reminders, lead to temporary reductions in anxiety, and therefore, increase the prolonged maintenance of anxiety. Among physically injured trauma survivors, there is evidence that avoidance may also be maintained by pain as noted in the earlier models of chronic pain and PTSD [30,35-36]. Avoidance in physically injured trauma survivors is also believed to be maintained by physical disability [37] and physical disfigurement [38]. Avoidance can be demonstrated as restriction in activities and possible pain medication overuse and is then maintained by fear, pain, and ruminations about the past.

When examining these factors, we can see that there are different avenues to approaching care with Veterans. A Veteran presenting for mental health treatment may only be ready to accept treatment for chronic pain because it may be too emotionally overwhelming for the patient to even consider engaging in trauma-focused psychotherapy to address PTSD. With some relief of physical pain and a deeper understanding of how PTSD can drive chronic pain, patients can then be better prepared to take the next step in PTSD treatment. The development of trust will naturally occur as we meet our patients, and it can then become possible for them to begin trauma-focused therapy for PTSD. On the other hand, some patients may present with PTSD symptoms that are the primary focus of attention and will say that they can live with their chronic pain. It is not uncommon for a clinician to hear that physical pain is something that Veterans learned to tolerate during military training so that they would be able to endure sleep deprivation, terrible weather conditions, and extreme physical exhaustion in order to accomplish missions during combat action. They now identify that the physical pain is limiting at times; however, they feel far more distressed by their PTSD symptoms. These patients may be ready to engage in trauma-focused therapy in order to find some emotional relief from disabling combat-related thoughts and images. For these patients, it has been my experience that, with completion of traumafocused PTSD therapy, their ability to tolerate and live with their chronic pain symptoms also improves to a significant degree.

\section{Blast Injuries}

For OIF/OEF Veterans, blast injuries have resulted in a devastating, complex array of injuries. The combination of PTSD symptoms, chronic pain, and postconcussion syndrome has been found to be unique to OIF/OEF Veterans [39-41]. This constellation of comorbid illnesses is more common in patients with blast injury and appears to be more challenging to address than each condition alone. Given the effect of these blasts, not only the 
risk of the inherent physical injuries exists, but also numerous mechanisms for potential exposure to the psychological and emotional effect of these traumas can then result in the development of PTSD [42]. Review of the article on PTSD and traumatic brain injury by Capehart and Bass (p. 789) will provide more detailed information about this specific topic.

Previous studies have shown that severely injured patients who require extended days of hospital care appear to be more likely to develop PTSD [43-44] and benefit less from traditional cognitive behavioral therapy (CBT) than patients who are less injured [45].

Servicemembers injured by blasts exhibit a broader spectrum of physical injuries that result in higher levels of hospital admission and discharge following return from combat action. These Veterans are also more likely to be prescribed opiate analgesics for the management of their pain symptoms. They also exhibit reduced improvement in pain intensity posttreatment than those Veterans who were not exposed to blasts during combat action. Note that there were much higher rates of PTSD and other psychiatric diagnoses in those injured by blasts than in those injured by other means, such as combat injuries other than blast and noncombat and nonblast injuries [46]. Combat Veterans with chronic pain and PTSD are hyperaware of bodily sensations, resulting in greater severity scores of chronic pain.

\section{Comorbid Disorders in PTSD and Chronic Pain}

Co-occurring disorders for individuals with both PTSD and chronic pain are also prevalent and can lead to greater functional impairment and disability. Depression occurs in nearly half of all of those who are receiving treatment and services for chronic pain. Notably, pain is also present in up to two-thirds of all of those who are treated for depression [47]. Depression is common with both PTSD and chronic pain. Fatigue and reduced activity levels exacerbate and maintain both PTSD and chronic pain symptoms. Among chronic pain patients, depression prevalence rates were estimated at 30 to 54 percent, much higher than in the general population. Depression may result as a consequence of pain, may precede the pain, and may be related to the maintenance of pain. A biopsychosocial approach to pain will best recognize what is likely a reciprocal relationship between emotional disturbances and pain [48-49].

Substance use disorders are also found at relatively high rates in those with chronic pain. In a population of patients treated for opiate addiction who are maintained on methadone, the rates of chronic pain are reported at approximately 37 to 60 percent [50]. Alcohol and other substances are also commonly used to cope with the mental health effect of military deployment, including the selfmanagement of depression, anxiety, PTSD, and chronic pain [51-52]. It is also found that substance use disorders are underrecognized in those returning from deployment. Self-medication with alcohol and drugs is a common reaction among people with PTSD and chronic pain; the consequences can be hazardous, especially with the combination of alcohol, prescription pain medications, and centrally acting anxiolytics. The cycle of avoidance in both PTSD and chronic pain is fueled by overuse or misuse of prescription pain medications and this concerning issue will be discussed later in this article. The VA has responded to the underrecognition of substance use disorders in all Veterans by aggressively promoting screening, education, prevention, and treatment of substance use disorders for all Veterans [53].

\section{Steps to Integrated Care Approach}

Given the high prevalence of comorbid illnesses in Veterans with both PTSD and chronic pain, we are tasked to look closely at integrated care models. Integrated treatments for patients with PTSD and chronic pain should, most importantly, focus on the unique experiences of the individual Veteran and the contributions of his or her physical, psychological, emotional, and spiritual makeup. It is critical to treat the whole person in order to gain a further understanding of the effect of trauma on the development and maintenance of both chronic pain and PTSD [54-55]. For our patients to achieve recovery and be able to move forward in their lives as they heal from both emotional and physical pain, we as mental health providers must help them become keenly aware of how their thoughts affect all aspects of their lives. Through the development of awareness with education about the intersection of PTSD and chronic pain, our patients can become more mindful and tuned in to how they are emotionally affected by their external environmental triggers and by their internal emotional triggers [56]. By working closely with patients to raise their awareness of internal and external cues that drive physical pain or trigger PTSD symptoms, such as nightmares or intrusive thoughts, we can effectively help our patients acquire the necessary skills to allow more positive coping. 
Prior to 2010, in the absence of treatment guidelines for PTSD and chronic pain, Wald et al. suggested modifying conventional protocols with pain treatment, including psychoeducation, relaxation strategies, and cognitive restructuring, delivered before PTSD treatment [57]. The general approach was to focus on the treatment of one illness and then approach the second illness with the hopes that this serial care plan would be able to provide the best clinical outcomes for the patient.

Research has also suggested that biofeedback (BF) is an effective pain treatment, but insufficient as a PTSD treatment [58-59]. There are no findings on the efficacy of treatment protocols addressing comorbidity in PTSD patients; however, there is information to be learned from research studies with traumatized refugees. Comorbid PTSD and chronic pain have been reported in 76 percent of traumatized refugees seeking treatment [60]. Factors complicating treatment for this population include culturespecific symptom presentations, language barriers, and differences between patients' and therapists' expectations about treatment [61]. These factors can also be translated to the provision of care for servicemembers and Veterans. Veterans strongly and preferentially identify with being part of a separate culture, and they often may have different expectations about treatment than civilian providers. $\mathrm{BF}$ was selected as a treatment option for the refugee population because CBT for both PTSD and chronic pain is heavily language-based and can be a barrier to the treatment of refugees. BF is relatively independent of cultural variations and the immediate physiological feedback can prove to be an advantage for the specific population of Veterans that experiences comorbid PTSD and pain.

Dahl et al. found that acceptance of the intervention was high and dropouts were unrelated to treatment [60]. The physiological orientation of the intervention allows validation of the patients' illness as somatic and enables them to experience the ability to control their symptoms, thereby directly confronting stigma associated with seeking treatment for "something in one's head.” Regaining a sense of mastery over their symptoms can help to modify the sense of uncontrollability experienced by those with both PTSD and chronic pain as described in the Triple Vulnerability model of PTSD and chronic pain. As expected, there was no reduction in PTSD symptoms; however, general psychopathology was lower at the 3-month follow-up. This suggests that BF may be an adjunctive treatment for PTSD through induction of relaxation and reduction of sympathetic arousal, but it is not a primary treatment. The implementation of BF in an integrated care model to treat PTSD and chronic pain may prove to be a solid starting point in treatment planning for patients.

\section{VA/DOD CLINICAL PRACTICE GUIDELINE FOR MANAGEMENT OF POST-TRAUMATIC STRESS}

Understanding the development and maintenance of PTSD and chronic pain along with the formulation of this complex relationship is often overlooked in clinical practice by primary care providers, mental health providers, and chronic pain providers. Given that rates of pain for Veterans with PTSD are high and that comorbid disorders are common and often lead to worse outcomes with a prolonged and severe course of illness, the VA/DOD clinical practice guideline for the management of PTSD was revised in 2010 with a special section devoted to the management of pain [62]. The interaction of these two disorders challenges all of us as clinicians, working in a variety of different clinical settings, to examine our current practice models to ensure that the Veterans we serve are provided excellent treatment at each point that they access our systems of care. Improving awareness and understanding of these two conditions and their intersection only helps to enhance provider satisfaction and improve clinical outcomes for patients.

The recommendations based on consensus of a working group of clinical experts for the PTSD clinical practice guideline include a series of 10 recommendations for the management of PTSD and chronic pain. Each is briefly outlined and discussed.

\section{Recommendation 1}

The first recommendation suggests obtaining a pain assessment using a 0 to 10 numerical pain rating scale, with 10 being the worst pain ever experienced. Pain scores $\geq 4$ are considered to require clinical attention and further examination. This is a subjective scale and takes the score reported by the patient at face value based on self-report of their pain experience. The pain assessment is reassessed throughout clinical care and allows changes to the individual's treatment plan to be made through collaboration based on the reported outcome.

\section{Recommendation 2}

A thorough biopsychosocial history and assessment for other medical and psychiatric illnesses is the second 
recommendation. Important components of the assessment process include a comprehensive suicide and homicide risk assessment. Specific questions about alcohol and substance use, such as over-the-counter medication; caffeine; herbal remedies; and prescription drugs, including controlled substances such as narcotic pain medications and benzodiazepines, is also important to the development of a comprehensive and safe individualized plan of care that also takes patient preferences into consideration.

\section{Recommendation 3}

The third recommendation includes a comprehensive assessment of the nature of the pain and determines the likely etiology, such as musculoskeletal and/or neuropathic pain, along with identifying the locations, quality, quantity, triggers, intensity, and duration of the pain and the potentially aggravating and relieving factors.

\section{Recommendation 4}

The fourth recommendation includes an evaluation of the effect of pain on function and activities, including pain-related disability or interference of pain with daily activities. Some individuals may report pain at a relatively high level; however, their overall functional impairment may not be evident because they may have learned to live with their pain and have found adaptive ways to cope with their pain. In these scenarios, pain does not adversely affect their overall quality of life. It is important to not only obtain a total pain score but also to relate this pain score to the overall reports of functional ability and life quality.

\section{Recommendation 5}

The fifth recommendation includes an assessment that identifies the avoidance behaviors that contribute to emotional distress and/or impairment in functioning. These pain-related avoidance behaviors may include reduced activity caused by pain that is exacerbated with daily activities, thereby leading to deconditioning, further reduction in activity, and increased difficulty reengaging in previously enjoyed activities because of pain-related fears. These avoidance behaviors can also include the avoidance of certain places and situations that may trigger traumatic thoughts and images, such as being in crowded places or on busy highways or jogging in a woody or marshy environment that is similar to previous combat experiences. Many individuals with PTSD and chronic pain will report avoidance of many previously enjoyed activities and the associated negative toll on their life, their self-confidence, and their relationships with their loved ones.

\section{Recommendation 6}

Management of pain should be multidisciplinary as part of the sixth recommendation. This should address the physical, social, psychological, and spiritual components of pain in an individualized treatment plan that is specifically tailored to the patient and type of pain. A team of clinical providers with varying expertise and clinical focus can be extremely helpful to the development of a comprehensive plan of care that can be implemented through the mechanisms that are available within multidisciplinary care teams. As previously mentioned, an important component of this multidisciplinary approach is to take into consideration patient preferences and to have a number of different treatment options available that will fit best with the individual patient and his or her goals for recovery.

Selection of treatment options should also balance the benefits of pain relief with possible adverse effects on the individual's ability to participate in and benefit from PTSD treatment. Narcotic pain medications have a number of side effects, including, but not limited to, sedation, cognitive impairment, weight gain, constipation, and exacerbation of comorbid sleep difficulties such as sleep apnea. Cognitive impairment, sleep difficulty, and sedation are the primary adverse effects that may interfere with an individual's ability to fully engage in and benefit from the evidenced-based treatments for PTSD, including cognitive processing therapy (CPT) and prolonged exposure (PE) therapy.

\section{Recommendation 7}

The seventh recommendation focuses on balancing the risks of pain control with the overall benefits. Often, patients will present for treatment in a PTSD clinical care area with reports of excessive fatigue, difficulty sleeping, sexual dysfunction, and memory trouble. It can be quickly assumed that the symptoms of PTSD can drive some of these reported complaints and the reflex action may be to increase sleep medications or adjust antidepressant agents to address what could be considered symptoms of depression or PTSD. Stepping back and inquiring into pain medication use and how the medications are taken by the individual with PTSD can be very helpful. It is not uncommon to hear from patients that they may take extra doses of their pain medications at night to help improve sleep for fear of going to sleep because of nightmares. 
Clinicians may also hear that patients are not taking their pain medications as prescribed for fear of running out of the medications and then the fear of going into narcotic withdrawal if they do not receive their new prescription on time. Some patients with both PTSD and chronic pain will also report taking as-needed narcotic pain medications to treat re-experiencing symptoms of PTSD. Although psychiatrists and mental health providers may not prescribe narcotic pain medications, there is a unique opportunity, through the development of trust and rapport, for mental health providers to be able to provide feedback to patients about how they can safely take their medications and attend to the current presenting symptoms. Psychiatrists should also be able to look at the presenting symptoms and/or complaints and make changes to the treatment plan should patients report taking their narcotic pain medications other than as prescribed. Those who prescribe pain medications to patients with PTSD and chronic pain will appreciate the collaboration from psychiatry and the patients will benefit from the combined attention to their recovery.

\section{Recommendation 8}

The eighth recommendation approaches the treatment of musculoskeletal pain syndromes with correction of the underlying condition and treatment with nonsteroidal anti-inflammatory drugs (NSAIDs). Rush et al. stated that treatment with some NSAIDs may prevent the antidepressant action of selective serotonin reuptake inhibitors (SSRIs) [63]. These studies showed that SSRI antidepressants increase brain levels of cytokines and a small protein known as p11, the effect of which is abolished by NSAID cotreatment. NSAIDs antagonize both biochemical and behavioral responses to SSRIs for the treatment of depression. The effect on the use of NSAIDs for musculoskeletal pain in patients receiving treatment for PTSD with SSRIs has not been researched. Rush et al. believe that reduced use of NSAIDs by physicians in severely depressed patients being treated with SSRIs would significantly improve positive outcomes from this major class of antidepressants [63]. Clinicians should balance the therapeutic benefits of NSAIDs with the potentially negative consequences of antagonizing the efficacy of antidepressants in patients with depression [63].

\section{Recommendation 9}

When clinically appropriate, the ninth recommendation includes the use of nonpharmacological modalities for pain control, such as massage; BF; physical therapy; and complementary and alternative medicine (CAM) modalities such as yoga, meditation, and acupuncture. To manage both PTSD and chronic pain, it is crucial to develop an individualized treatment plan with patient involvement in all aspects of the care plan. It is important to be where the patient is at in his or her care plan because recommendations that we may propose based on the evidence and clinical research may not match the desired plan of care that our patients would like to follow. Having options available to improve quality of life for those patients who prefer CAM modalities for the management of pain will only help to improve and solidify the therapeutic relationship with the hopes that this will lead to improved outcomes for the patient. Perhaps this can also be viewed as an initial step in tackling the disabling avoidance that paralyzes so many patients with PTSD and chronic pain. If our patients are able to achieve small successes, regaining their confidence and strengthening their self-esteem, we may be able to help them take the next step to engage in the evidenced-based psychotherapies for PTSD.

Some clinically relevant pain coping strategies include activities that increase patients' abilities to manage their symptoms and improve their daily functioning. Clinicians may recommend activities such as physical exercise, social interactions, and recreational activities. Hyperarousal in the setting of PTSD and chronic pain can be quite disabling; therefore, employing relaxation therapy can be an effective and important coping strategy for the self-management of both of these conditions [64]. Clinicians should be able to provide education and training in relaxation methods such as diaphragmatic breathing, progressive muscle relaxation, and autogenics. These positive coping techniques have the ability to serve a dual purpose for a specific subset of patients who are willing and ready to engage in CAM modalities. These modalities have been shown to help patients cope with chronic pain and can also help individuals cope with the disabling symptoms of PTSD.

\section{Recommendation 10}

The tenth recommendation advises caution in the use of centrally acting medications for the treatment of chronic pain in patients with PTSD because these medications may cause confusion and deterioration of cognitive performance, thereby potentially interfering with the recovery process. The 2010 VA/DOD clinical practice guideline for 
managing opioid therapy for chronic pain advises the use of opioids for patients with moderate to moderately severe pain after measuring whether the benefits of opioid therapy are likely to outweigh the risks. In prescribing opioids, it is crucial that the patient is fully informed and consents to therapy and that very clear and measurable treatment goals are established. Centrally acting agents must provide effective pain relief with the best benefit-to-harm profile for the individual patient [65]. If pain relief is not provided with narcotic pain medications, then the plan of action and approach should be modified.

This is a very important recommendation given that many Veterans receive treatment for their chronic pain problems within primary care settings, and often, primary care providers may not have ready access to the expertise of pain specialists and mental health clinicians. It is not uncommon to hear from very busy primary care providers that they have a duty and moral obligation to treat a patient's chronic pain when the pain score exceeds $\geq 4$. That is absolutely the case because this pain score requires clinical attention and further examination. However, for many of these clinicians, their recommended treatment often results in providing a prescription for an opiate pain medication given their time constraints and their ethical obligations to address pain in their patients who are suffering. The importance of the biopsychosocial evaluation must be stressed in this setting so that the patient's pain experience is fully defined prior to recommending treatment options. The best treatment is not likely to be a prescription for an opiate pain medication for patients with both PTSD and chronic pain. Integrated care models will prove to be of incredible assistance to all of our primary care providers because these clinicians also individually struggle to manage the complexities of both PTSD and chronic pain.

\section{SPECIAL FOCUS ON CENTRALLY ACTING PAIN MEDICATIONS IN PTSD AND CHRONIC PAIN}

When examining prescription pain medication use in patients who have PTSD and chronic pain, we can clinically see how this can pose challenges to both the patient and the provider. As mental health providers, we often see opiates being misused by our patients in order to manage emotional distress and avoid combat-related intrusive thoughts and memories. Seeing this happen with patients who have PTSD can be quite challenging to primary care and mental health clinicians, along with the patient's family members. It can be helpful to understand the path that may lead to the initiation of a prescription pain medication and the process that should be in place to identify problems with patients sooner rather than later. The importance of interdisciplinary care and communication cannot be stressed enough in these particular cases.

For the most part, psychiatrists will not be the prescribers of narcotic pain medications; however, gaining an understanding of the process and screening in place to prescribe pain medication is quite relevant to the mental health treatments we provide. Before a narcotic pain medication is prescribed, a comprehensive assessment that includes a complete history and physical examination with clinically indicated diagnostic studies should be conducted. Completing a risk assessment for aberrant drugrelated behaviors and using risk stratification instruments such as the Opioid Risk Tool and Screener and Opioid Assessment of Patients with Pain (version 1 and revised) can prove to be very beneficial [66-68]. Clinicians who are providing mental health care to patients with PTSD and chronic pain will likely not be the providers prescribing pain medications; however, they are in a unique position given the development of trust and therapeutic rapport that is the foundation of the treatment of PTSD. Mental health providers have the opportunity to work alongside the clinicians who are prescribing pain medications to offer valuable input to the prescribers and to the patients. Inquiring into opiate use can provide a wealth of information on the Veteran's current status in regards to both chronic pain and PTSD, along with his or her overall quality of life and functional ability. This is also an opportunity to assess a patient and determine whether or not there is a problem with addiction to pain medications since this will require a change in plan of care that should most definitely be coordinated with the prescribing provider.

Some questions that can be asked during the mental health evaluation and treatment process include-

- How often do you take more pain medication than you are supposed to?

- When was the last time you took additional doses of pain medications so that you could fall asleep at night?

- How often have your pain medications been lost or stolen?

- How often has more than one doctor prescribed pain medication for you at the same time?

- How often do you run out of your pain medications? 
- Do you call for early refills or do you wait for your next scheduled appointment?

These questions and the answers provided by the patient can offer valuable information into the patient's recovery. It is common to hear from patients with PTSD and chronic pain that they frequently run out of their narcotic pain medications, feel ashamed, and do not call their prescribing provider. These patients routinely experience the uncomfortable effects of opiate withdrawal, including diarrhea, muscle aches, abdominal cramping, nausea, and increased anxiety and agitation, which often exacerbate PTSD symptoms. Again, another reflex action may be to increase the dose of sertraline to address the surface PTSD symptoms, when in fact, the patient could benefit from some ibuprofen or perhaps clonidine, loperamide, and/or Bentyl to target what are actually opiate withdrawal symptoms. Posing some of the above questions will also let the mental health provider know how severe and intense the patient's PTSD symptoms are at the present time. If patients report taking too much pain medication and then running out, it can alternatively be helpful to consider increasing their SSRI and/or referring the patient for further psychotherapeutic intervention to manage their PTSD symptoms before the patient attempts self-management of their PTSD symptoms with narcotic pain medications. Working with the patient who has PTSD and chronic pain and pointing out the cycle of avoidance can help some patients engage in the necessary trauma therapy services. In essence, patients may be managing their PTSD symptoms through self-medication, by avoiding their feelings and numbing their intolerable emotions with narcotic pain medications and then, unfortunately, leading themselves down a dangerous path of self-destruction.

There is a complex interaction between the person at risk and properties of certain drugs, such as the long- versus short-acting narcotic pain medications. Drug properties and prescribing patterns for pain medications should be taken into consideration when working with patients who have PTSD and chronic pain. Short-acting pain medications have a more rapid onset and offset of action, with an increased propensity for the development of addiction than longacting agents. Selecting pain medications with a longer half-life can help to possibly curb addiction potential and medication misuse.

There are also opportunities for intervention in reference to provider prescribing patterns based on clinical observations in patients with both PTSD and chronic pain. Prescriptions written for as-needed dosing can sometimes cause confusion for some patients with PTSD. Patients have reported that they will hold off on taking their medications so that they can have additional doses available should they have problems with re-experiencing symptoms, such as nightmares or intrusive thoughts. Some patients have even reported taking their pain medications following disagreements or arguments with their family members as a strategy to manage their anger and irritability. Scheduled doses of pain medications at specific times of the day can help to modify the risk of confusing chronic pain symptoms with normal emotional or psychiatric symptoms for patients with both PTSD and chronic pain. Questions about how patients take their pain medications can provide very fruitful information for mental health providers because they can learn more about the specific symptoms of both PTSD and chronic pain for patients throughout the day and how they may attempt to selfmanage their own psychological and physical distress.

Knowledge of the nonmodifiable risk factors for addiction, such as a family or personal history of substance abuse or addiction, a personal psychiatric history of any kind, age (younger age carries a greater risk potential), current status as a smoker, and a personal history of preadolescent sexual abuse, can yield helpful information in the care of patients with both PTSD and chronic pain. If a mental health provider working with a Veteran who has PTSD and chronic pain has an understanding of the specific aberrant medication-related behaviors, this knowledge will only help to integrate and coordinate care with the primary care providers. Some of these specific aberrant behaviors include, but are not limited to [69]

- Requests for higher medication doses without improvement in pain status with dose escalation.

- Early refills.

- Extra medication requests because of frequent travel or inability to attend more frequent visits.

- Lost medications.

- Multiple unsanctioned dose escalations.

- Unexpected urine toxicology results showing absence of opiates or presence of illicit substances.

- Deterioration in occupational, family, or social functioning.

- Resistance to changing or tapering opiates, despite a number of adverse effects to the medications.

- Refusal to comply with urine drug screens as needed during treatment.

- Concurrent abuse of alcohol or illicit substances. 
- Use of multiple physicians and pharmacies.

Evidence of the above aberrant behaviors for a patient who is prescribed opiates requires further discussion and assessment of substance dependence while coordinating this plan of care with the prescriber of the pain medications. The clinical expertise of substance abuse specialists can be helpful in these types of situations.

With the use of narcotic pain medications, ultimately the goal of treatment is to provide sustained analgesia and improvements in sleep and quality of life. It is crucial to carefully screen patients being considered for long-term opiate therapy and be able to identify patients who may have difficulties with managing opiates. Even if the mental health provider may not be the prescriber of pain medication, awareness of these risk factors when patients who present in different settings, such as mental health, and report a variety of symptoms that may or may not be side effects of narcotic pain medications can only help to provide high quality of service to Veterans. Awareness of these risk factors and the presenting characteristics of addiction can be especially helpful in developing the best plan of care for patients with both PTSD and chronic pain.

Importantly, patients with both PTSD and chronic pain should not be denied access to opiate therapy; however, they may require more focused monitoring with increased frequency and intensity of visits with urine drug screens to confirm the presence of the prescribed medication and to confirm the absence of illicit substances given the increased risk for development of a substance use disorder. With the prescription of any medication for patients, whether it is a narcotic pain medication for chronic pain or an SSRI for the treatment of PTSD, the medication treatment must provide the following:

1. Analgesia and/or modification of PTSD symptoms.

2. Improvements in activities of daily living with reduction in avoidance behaviors.

3. Careful monitoring of adverse effects, such as sedation, cognitive impairment, constipation, sexual dysfunction, and then an adjustment in plan of care as indicated.

4. Monitoring for aberrant drug-related behaviors, such as running out of medication, overusing medications, and seeking prescriptions from multiple providers [70].

Evidence of aberrant drug-related behaviors requires decisive action, and in most cases, continued prescription of an opiate pain medication is not recommended given the inherent health risks, including accidental overdose. There is a greater rate of accidental poisoning deaths among Vet- erans than nonveterans, and the risk of accidental poisoning death relative to the general population is larger than that of suicide. Opiate medications are frequently the substance responsible for accidental poisoning death in VHA patients. We must look closely at prescription pain medication use in our at-risk patients by conducting biopsychosocial assessments and comprehensive risk assessments and examining strategies to prevent overdose in patients with PTSD and chronic pain [71].

\section{PTSD, Chronic Pain, and Addiction}

For Veterans with PTSD, chronic pain, and opiate addiction, some viable options have been effective during clinical work with this patient population. Engagement through immediate or same-day substance abuse consultation is recommended. Motivational interviewing can help to address ambivalence about treatment. Following detection and assessment for opiate abuse or dependence, the option of combined buprenorphine and naloxone (Suboxone) can be considered. Along with maintenance pharmacotherapy for opiate addiction, voucher- or monetary-based incentive programs, CBT, and relapse prevention are generally efficacious [72-73]. Acceptance and commitment therapy have also been found to be effective for pain management and substance abuse treatment [74-76].

Managing addiction with combined buprenorphine and naloxone offers opportunities for pain management based on the mechanism of action of the medication [77]. With agonism at the mu opioid receptor, moderate pain relief can be achieved. Antagonism at the kappa receptor functions to minimize hyperalgesia. This treatment may be inferior to higher-dosage opioids for pain relief because it is only a partial agonist at the mu receptor; however, by breaking the cycle of intoxication, withdrawal, and functional impairment for those with opioid addiction, this treatment alone can help to achieve stabilization of a potentially deadly addiction and can modify the physical and emotional distress of addiction that can exacerbate PTSD symptoms and chronic pain.

Pain relief from buprenorphine diminishes above doses of $4 \mathrm{mg}$ and analgesia typically lasts 8 hours per dose. Effective pain relief and stabilization of opioid addiction for those with PTSD, chronic pain, and addiction have been found to occur at doses of $4 \mathrm{mg}$ taken sublingually three times per day. Additional pain management modalities are also recommended, including, but not limited to, physical rehabilitation with exercise and stretching as tolerated, nonnarcotic medications to manage pain, BF, 
behavioral activation (BA), and acceptance and commitment therapy. Chronic pain complicates management of opioid addiction and PTSD. Treatment collaboration following an integrated care model will help patients to achieve adequate pain relief and improvement in overall quality of life and functioning with successful stabilization of opiate addiction and the associated physical and emotional difficulties.

For patients with PTSD and chronic pain, it is also important to differentiate between opioid use disorder and pseudoaddiction. The difference has clear treatment implications for pain management and substance abuse treatment. Pseudoaddiction is described as opioid-seeking behavior with requests for dose escalations caused by inadequately treated pain [78]. This similar pattern can also be seen in patients with inadequately treated depression and anxiety disorders such as PTSD [79]. This again triggers the need for a comprehensive biopsychosocial assessment and an integrated interdisciplinary care treatment approach. Pseudoaddiction resolves with adequate relief of pain, at times not even with opioids as the treatment option, and does not involve maladaptive patterns of substance abuse that can lead to clinically significant impairment. It can therefore be hypothesized that relief of anxiety and depressive disorders through evidence-based psychological and psychiatric treatment for PTSD can function to modify aberrant drug-related behaviors.

\section{Pharmacological Management of PTSD and Chronic Pain}

Pharmacological management of chronic pain in Veterans with PTSD is one component of treatment; however, no studies evaluating pharmacotherapy and functioning for patients with comorbid pain and PTSD have been examined to date. Pharmacological management has typically been completed through side-by-side management with the most common first-line treatments for pain, including acetaminophen, NSAIDs, opioids, tramadol, anticonvulsants, tricyclic antidepressants (TCAs), and serotonin-norepinephrine reuptake inhibitors (SNRIs).

The first-line pharmacotherapy for PTSD includes SSRIs, with Food and Drug Administration (FDA) approval for the use of sertraline and paroxetine for the treatment of PTSD with limited support for their efficacy in the treatment of pain. Venlafaxine is also a first-line treatment for PTSD within the class of antidepressant agents referred to as SNRIs and is also effective in the management of some chronic pain syndromes.
Based on the current research available, the treatment and pharmacological management of PTSD and chronic pain have historically been off-label and driven by clinician prescribing patterns with reported relief and modification of PTSD and pain symptoms from treated patients.

\section{MOST COMMON PAIN COMPLAINTS IN PATIENTS WITH PTSD}

The three most common pain complaints reported to providers working in the PTSD clinical program in Tampa, Florida, are back pain, headaches, and neuropathic pain. This article examines pharmacological management and therapeutic recommendations to modify the pain experience because pain can drive the constellation of PTSD symptoms for patients. For many of the patients treated in this clinic, their preference is to continue their medical and pain management treatment with the providers with whom they have developed and established trust and rapport. Often we may recommend referral to a pain management program but this is declined by many patients, citing that they are unfamiliar with the program and they believe that they are "too sick or completely broken" if they need to be referred to another clinical program. By attempting to alleviate suffering and provide some measure of comfort to patients, some treatments are initiated in the PTSD clinical program with the hope that this can help build a bridge to more intensive pain management services as clinically indicated.

\section{Back Pain}

Back pain is one of the leading causes of long-term disability in the United States today. Back pain can be triggered by a number of different injuring mechanisms, including direct injury to the vertebrae, facet joints, nerve roots and/or muscle and connective tissue damage. For many patients, there is no direct relationship between physical findings discovered on examination or diagnostic testing and the patient's perceived level of pain, disability, and psychological distress. If back pain is disproportionate to findings on examination, there tends to be a greater propensity toward the presence of an underlying depression and associated maladaptive cognitive patterns, including catastrophic thinking.

When treatment options are examined upon identification of the cause of the chronic back pain, recommendations include returning to activity as soon as possible to 
prevent the cycle of deconditioning and further difficulty returning to previous levels of activity. Starting with conservative management and then moving ahead is typically the best and most agreeable option for many patients. Exercises that are recommended by primary care providers and rehabilitation specialists include flexibility, range of motion, aerobic activities, and muscle strengthening exercises. Medications include NSAIDs, acetaminophen, tramadol, and some antidepressant agents provided there is a comorbid depression. Antidepressants with SNRI, such as venlafaxine and duloxetine, have proven to be viable options for the treatment of chronic back pain, whereas the SSRIs have not proven as effective for pain relief; however, sertraline, paroxetine, and venlafaxine are the only antidepressants considered first-line treatment of PTSD. Additional psychotherapeutic options include a course of CBT and teaching relaxation techniques, with some patients preferring CAM such as acupuncture, massage therapy, and/or yoga. Surgery and spinal cord stimulation are typically reserved for patients with minimal response to a range of the previously mentioned treatment options [80].

\section{Headache}

Headaches are the second most common report of ongoing pain and distress for patients in the Tampa PTSD clinical program. The most prevalent headaches are tension and migraine in origin. Tension headaches can be described as pressing and tightening, band-like, surrounding the head and bilateral in presentation. Some consider tension headaches a variant of migraine headaches and they are thought to arise from myofascial pain sensitivity and increased pericranial muscle activity. This can be brought on by both physical and psychological stress because emotional distress may contribute to muscle contraction driving the tension headache. These types of headaches are exacerbated by poor posture and other ergonomic factors, such as carrying loaded bags, computer work, and heavy military equipment such as headgear. Dental complications may predispose some people to tension headaches and they may need occlusal adjustments, splints, or masticatory exercises. Bruxism is common in PTSD and is also a side effect of SSRIs; this in itself can drive tension headaches. Abortive treatment strategies include NSAIDs, acetaminophen, and aspirin. Chronic tension headaches can respond to prophylactic agents such as TCAs, SSRIs, and SNRIs. Stress management, BF, relaxation training, dental referral, and CBT are also helpful strategies for some patients.
Migraine is a chronic disabling neurologic pain syndrome that requires optimal pharmacological care to restore patients to normal functioning and to prevent significant disability. PTSD is more common in chronic migraine than in episodic migraine. PTSD may be a risk factor for chronic headaches, with treatment of migraine headaches being complicated by the fact that patients react in different ways to medications. What may work for one patient may not work for another, especially in those with PTSD [81].

Acute migraine treatment involves the use of triptans or ergots. Triptans are serotonin agonists and caution must be used because of the risk of serotonin syndrome in patients with PTSD who are also taking SSRIs. Educating the patient about the signs and symptoms of serotonin syndrome is important to ensure safe management of migraine headaches. Patients should be instructed to take the triptan at the earliest onset of mild pain, before full-blown migraine, to maximize a sustained pain-free response. It is not uncommon for patients with PTSD to wait until they have a full-blown migraine episode before taking the triptan. Many will report that they felt they could work through the headache on their own; therefore, they waited too long to abort the episode. It is important to use the agent less than 10 days per month to avoid transformation to chronic daily headache and to avoid rebound headaches. NSAIDs, small amounts of caffeine, and antiemetics for additional relief of associated nausea can also be prescribed. Ergots (dihydroergotamine) come in injection and nasal spray formulations and are used in those who do not tolerate triptans; those who failed triptan therapy; or in those with prolonged, disabling episodes [82].

Daily preventive treatment for chronic migraine is typically recommended when the frequency or disability of migraine is high; when there is risk of neurologic injury (hemiplegic migraine); or when acute therapies are contraindicated, not tolerated, or overused. Preventive treatment for migraines decreases hyperexcitability by reducing cortical spreading and neuronal activation. The overall efficacy of prophylactic classes is similar and selection should be based on treating comorbid conditions.

Amitriptyline, propranolol, timolol, divalproex sodium, and topiramate are viable options for preventive treatment of migraines. The dual-action antidepressants have efficacy for migraine. For patients with PTSD, only venlafaxine is recommended as a first-line treatment. The SSRIs regarded as first-line treatments for PTSD have performed poorly for migraine prophylaxis. All of these medications, when 
used at appropriate doses for at least 2 to 3 months, yield approximately a 50 percent reduction in migraine frequency. Guidelines suggest starting with a low dose and treating to effect or the development of intolerable side effects. Other classes of medications, such as the calcium channel blockers (verapamil), SNRIs (venlafaxine), angiotensin-convertingenzyme inhibitors (lisinopril), angiotensin receptor blockers (candesartan), clonidine, NSAIDs, or natural supplements (magnesium, riboflavin, coenzyme Q10), have less evidence for the treatment of migraine headaches. CBT should also be recommend for patients with PTSD and chronic migraine headaches to help the patient achieve desired recovery and relief [83].

For patients who have failed pharmacological treatment modalities for the management of chronic migraines and for patients who prefer to not take oral medications, a referral to neurology for injection of onabotulinumtoxinA (BOTOX) as a headache prophylaxis in adults with chronic migraine can be a viable treatment option. BOTOX injections have been shown to reduce headacherelated disability and improve functioning, vitality, and overall health-related quality of life [84].

\section{Neuropathic Pain}

Neuropathic pain is the third most common report of pain in patients who receive treatment in our PTSD clinical program. Adequate treatment of neuropathic pain to reach desired pain relief for patients is difficult to achieve. The efficacy of drugs for neuropathic pain has been established in randomized clinical trials (RCTs) that have excluded patients with comorbid conditions and those taking complex medications. Application of the evidence can become quite difficult for the treatment of Veterans with comorbid disorders including, but not limited to, PTSD and chronic pain.

Neuropathic pain is very frustrating for many patients and treating providers because inadequate pain relief may lead to complete disability. Often, to modify the pain experience, complex pharmacology regimens are recommended after examination of the cause of the pain; attempting to modify or control comorbid medical conditions that can exacerbate neuropathic pain, such as poorly controlled diabetes; and examining additional factors to allow for development of an individualized plan of care.

For many of the patients in our PTSD clinical program, the most common causes of neuropathic pain are diabetes, Agent Orange exposure, vitamin B12 deficiencies, thyroid disease, alcohol use, chemotherapies, entrap- ment neuropathy (carpal tunnel, ulnar entrapment), and poststroke syndromes [85]. Aggressive action is taken to correct and control underlying medical conditions that can worsen neuropathic pain, such as repleting vitamin B12 levels, addressing alcohol use disorders, and improving hemoglobin A1c control for patients with diabetes.

The frequent neuropathic complaints include the following:

- Allodynia: Pain produced by nonnoxious stimuli; trying to go to sleep at night and experiencing intense pain upon placing the sheets on his/her feet.

- Hyperalgesia: Exaggerated pain response to noxious stimuli; walking barefoot on a gravel road feels like walking on hot charcoal.

- Dysaesthesia: Unpleasant sensation, not always painful; when patients have a difficult time describing their pain symptoms and may often say, "It just feels weird ... not normal."

- Paraesthesia: Pins and needles that can be described as sharp, stabbing, shooting, tingling discomfort and pain; frequently described as distracting and unexpected and leading to a feeling of uncontrollability and emotional distress.

Veterans with PTSD and neuropathic pain can experience significant functional impairment, including pain that interferes with sleep, and develop problems with balance, tripping, and falls, especially upon awakening at night after nightmares and then pacing the floors in their home. Determining the specific causes of a patient's sleep difficulties, such as neuropathic pain and/or nightmares, and then being able to offer modalities to modify his or her pain and other PTSD symptoms can be extremely helpful. We have also found that it is helpful for patients with PTSD and neuropathy to create a safe environment prior to going to sleep to reduce the risk of accidental injury and falls should they wake up at night. The hallways should be clear and a path to the bathroom and stairwell should be free of all items such as books, newspapers, shoes, and toys. Additional lighting can also help reduce the possibility of tripping and injury.

TCAs, gabapentinoids (including gabapentin and pregabalin), selective noradrenergic reuptake inhibitors (venlafaxine and duloxetine), and topical lidocaine are the firstline choices. Selecting an agent should also consider the patient's comorbid medical conditions and stability of any underlying mental illness given the risks of lethal overdose associated with TCAs. Additional agents are added as needed and with careful consideration and examination of 
potential drug-drug interactions. Second-line agents include opioid agonists such as methadone and tramadol, again with careful consideration of opioid use for patients with comorbid disorders and risk factors for addiction. Thirdline agents, FDA-approved for the treatment of neuropathic pain, include anticonvulsants such as carbamazepine, lamotrigine, topiramate, phenytoin, and valproic acid and in addition have been observed to have beneficial effect for the modification of emotional lability and irritability during clinical work with Veterans with both PTSD and chronic neuropathic pain. Additional third-line agents include antidepressants such as bupropion, citalopram, and paroxetine, along with topical agents such as capsaicinoid that inhibits the pain-eliciting substance $\mathrm{P}$ [86-88]. A thorough review of the patient's current medication profile, medical conditions, and potential adverse drug-related effects must be carefully considered and monitored before prescription of any of the above agents.

Alternative interventions for managing neuropathic pain include BF, hypnosis, relaxation techniques, tai chi with the ability to improve motor function and balance, acupuncture, and occupational therapy. Transcutaneous electrical nerve stimulation and sympathetic nerve blocks have also been used with some effect for patients with debilitating neuropathic pain.

\section{DISCUSSION}

The management of both PTSD and chronic pain has been challenging for both primary care providers and psychiatrists. Bridging the gap between mental and physical health truly requires a multidisciplinary approach because of the higher rates of morbidity and premature mortality compared with the general population [89]. People with serious mental illness are more likely to engage in unhealthy lifestyle practices, such as lack of physical activity, poor nutrition and overeating, smoking and other substance abuse, irregular and inadequate sleep, and failure to visit healthcare providers on a regular basis. Many of these unhealthy lifestyle practices, such as lack of exercise, impaired sleep, obesity, and smoking, only drive and exacerbate chronic pain symptoms. Given the changes in our current healthcare systems, it has become judicious for both psychiatric and physical healthcare providers to broaden their treatment patterns to address the whole person. An integral component of mental health services will be for psychiatric providers to make sure that the health status of all patients is assessed, that each individual has a primary care provider assigned, and that there is an effective mechanism in place for communication between the mental health and medical care providers. There is a growing need for a coordinated, multidisciplinary, holistic approach to bridge the gap between physical and mental health among patients with major psychiatric disorders and medical conditions such as PTSD and chronic pain.

Significant challenges face psychiatrists regarding the care of patients with mental illness and comorbid medical conditions. Both action and inaction in the case of medical illness for a patient who is treated in mental health can confer legal risks and liability. Psychiatrists have the greatest level of responsibility for medical conditions that may be the result of an action taken by the psychiatrist, such as the development of diabetes in a patient who is receiving antipsychotic medications [90]. The psychiatrist is therefore obligated to be aware of the medical risks of psychiatric medications and to assist with appropriate monitoring and, if necessary, implement corrective actions on behalf of the patient [91].

Psychiatrists are likewise responsible for being aware of medical illnesses or treatments that can exacerbate the psychiatric illness that they are treating, and they have a duty to ensure that these medical conditions are properly addressed. In the case of patients with PTSD and chronic pain, understanding the effect of centrally acting pain medications on the body and emotions is essential to the care of patients with comorbid illnesses. This awareness will assist in the development of a sound and holistic individualized treatment plan that will also allow for coordination with the primary medical providers. With the extensive electronic medical records within the VHA, this coordination of care may involve a brief note in the medical record that requests an electronic signature or acknowledgment of receipt by other medical providers involved in the patient's care. Alerting all providers responsible for the patient's care, either through a telephone call or electronic signature, allows for monitoring of the patient's status and ensuring follow-through to address the medical condition of concern that requires clinical attention.

An integrated health clinic for chronic pain, stressrelated depression, anxiety, and PTSD in Salt Lake City, Utah, was designed for the nonpharmacological biopsychosocial management of chronic pain and PTSD using CAM and mind-body skills also focused on lifestyle concerns that affect health, such as obesity and tobacco use 
[92]. This program offers psychological, social, spiritual, and physical healthcare using CAM therapies. Acupuncture, aquatic bodywork, stress management, hypnosis, meditation, qi gong, yoga, herb-drug interaction counseling, multidisciplinary weight management, and tobacco cessation classes were the foundation of therapies and classes offered. Each therapy and class correlates to a common philosophy of calm mind, thought and body awareness, use of pain and stress-management techniques, and promoting self-efficacy to enhance coping and wellness behaviors. This integrative care clinic and program offers an effective reduction in pain-related psychopathology, depression, and anxiety and improved quality of life for up to 6 months or more upon completion of treatment. This study was not designed to evaluate the effectiveness of the individual therapies but was developed to determine the benefit of the program as a whole. Patients were empowered to use self-management tools to modify their pain and emotional distress. An RCT is needed to infer cause and effect or assess overall treatment effectiveness. Selection bias was also a factor, such as belief in a new treatment, because many of the patients had chronic PTSD and depression for extended periods of time. However, it is important to acknowledge the use of CAM therapies and their integration into conventional medicine because many patients request access to these therapy options. This is an innovative treatment approach and further research can prove to be beneficial to patients with comorbid illnesses such as PTSD and chronic pain.

One of the most efficient and efficacious treatments for PTSD is PE therapy, which involves repeated imaginary exposure to the traumatic memory and repeated in vivo exposure to safe situations that were previously avoided [93]. CPT has also been found to be an effective treatment for PTSD across trauma populations and has also been successfully adapted for use with Veterans with combat-related PTSD [94]. Because Veterans access our VA medical systems from multiple points of care, it has become essential for our healthcare systems to adapt to the changing needs of patients. Given the increasing number of male and female Veterans entering into the VA system of care and the comorbid illnesses such as PTSD and chronic pain, integrated care models have begun to flourish.

Integrated care models have become an important part of mental health care, with many Veterans first being screened and diagnosed with PTSD in primary care clinics. Unfortunately, the number of Veterans receiving an adequate treatment protocol for PTSD in mental health is few because of stigma and individual concerns such as travel, time, employment, and other competing priorities that interfere with full engagement in a course of evidenced-based treatment for PTSD [95-98].

Wagner et al. presented pilot data on a small randomized effectiveness trial that used an adaptation of BA for the early intervention of PTSD and depression among physically injured survivors of traumatic injury [99]. By blocking avoidance, BA is similar to in vivo exposure that is a component of PE therapy for PTSD and can be a useful technique for treating PTSD symptoms. BA differs from in vivo exposure in that BA keys in on activities that are reinforcing and consistent with the patient's goals as opposed to those activities that are avoided because of fear or anxiety. Because of the new restrictions faced by many of the seriously injured participants, more time was spent on goal setting. Attention was also given to the range of avoidance factors, such as fear, pain, physical limitations, shame, and maladaptive cognitions, along with substance abuse if conceptualized as an avoidance behavior.

Through activity charting and scheduling, participants were able to see the relationship between avoidance and/or inactivity and fear and/or depression. For some, avoidance was maintained by a fear of what others would think of them with their injuries and fear of possible reinjury. Behavioral assignments progressed from activities that could be done from bed (such as watching movies, reading, or using the telephone), to those from a chair (computer activities) to those that required increased mobility (such as walking downstairs, walking around the block, or running errands). The graded assignments allowed for initial success and then the ability to continue to push forward to more challenging activities to eventually meet the patient's desired goals.

This study showed that increases in guided activity can break the patterns of avoidance that function to maintain PTSD. Patients engaged in BA showed improvement in PTSD symptom severity and improvement in physical functioning posttreatment. The BA group did not demonstrate significant improvements in depression, and this was felt to be related to the limited number of sessions (average 5.75) and that treatment outcome studies for depression provided up to 20 sessions of therapy [100]. Posttreatment PTSD scores remained elevated despite the effect of BA on PTSD severity. It is proposed that high levels of previous and recurrent traumatic life events 
attenuate response to treatment intervention [101]. It is possible that more than six sessions could be required for complete remission of PTSD symptoms among the seriously injured patient population. Zatzick et al. proposed that the focus on increasing meaningful activity based on individual goal setting may be helpful for injured trauma survivors who face a number of new life obstacles [101]. Small successes can have much greater payoffs as individuals progress in treatment. Given the traditional masculine stereotypes of combat Veterans, BA may also be effective for military populations who may struggle with stigma by allowing them to access their emotions for trauma processing therapy.

In 2010, BA as a treatment for PTSD and depression [102] was implemented as a primary care-based treatment following the protocol developed by Wagner et al. [99] with more focus on PTSD and depression. The initial idea was to be able to offer an effective treatment in primary care that would allow more patient engagement, thereby maintaining fidelity to treatment and improving clinical outcomes. The results revealed significant and meaningful reductions in PTSD symptoms found on structured clinical assessments and self-report measures. PTSD treatment gains were maintained at 3-month follow-up. There were meaningful improvements on depression and quality of life measures and Veterans reported a high satisfaction with treatment.

Following the work completed by Wagner et al. [99] that examined BA as an early intervention for PTSD and depression among physically injured trauma survivors, an integrated treatment approach for Veterans with comorbid PTSD and pain was initiated as a pilot study [103]. Using components of CPT for PTSD and CBT for chronic pain management, Otis et al. developed a 12session integrated treatment for PTSD and chronic pain [103]. Weekly readings and assignments were used and participants received pre- and posttreatment evaluations using measures of pain, PTSD, physical disability, and psychological distress.

There were a limited number of participants in this study, with only three completing the pilot study; however, an RCT is currently being implemented to examine the integrated treatment versus stand-alone treatments for PTSD and pain, such as CBT for pain, CPT for PTSD, and wait list control versus the integrated care model. There were many challenges faced during the pilot program, which included issues related to difficulty establishing trust, problems with treatment attendance, avoidance, and diffi- culty completing the homework assignments. There was evidence of reduction in PTSD symptoms and improvements in symptoms of chronic pain for some participants. If future RCTs reveal that the positive effects of integrated care are greater than the effects observed in patients who receive treatment for either PTSD or chronic pain alone, then this approach could have direct benefits on access to care and improvements in care for Veterans with comorbid PTSD and chronic pain.

\section{CONCLUSIONS}

The effect of OIF/OEF on the physical and emotional health of returning servicemembers has been personally witnessed by their loved ones and the medical providers who care for these former servicemembers. We are all constantly challenged to come up with new and innovative ways to help Veterans strengthen their resilience, enhance their recovery, and promote their reintegration. We have learned a lot from all generations of war Veterans over the years and we have become versed in the considerable burdens that PTSD and chronic pain, along with other comorbid medical conditions, place on Veterans who have sacrificed for the service of our country. It is well known that untreated PTSD is specifically related to chronic physical and other mental health problems and that without treatment, the individual and his or her loved ones will unnecessarily struggle and suffer.

Integration of medical and mental health care, at all points that Veterans access VA healthcare services, will provide Veterans with the gateway to achieving life satisfaction and healing from both PTSD and chronic pain. Independent of the combat theater in which a Veteran has served, it is crucial that clinicians and researchers develop more integrated treatment programs and strategies to meet the needs of Veterans with PTSD and chronic pain. Pharmaceutical RCTs focused on these comorbid conditions are a must, along with further refinement of the integrated psychotherapeutic techniques currently in the literature.

All Veterans who have honorably served our country have earned and truly deserve the most comprehensive, individualized, and holistic treatment approaches that can be made available. We are all challenged to increase our knowledge and expertise in these clinical areas as Veterans access care through a variety of different clinical settings. We should be able to meet them at each point of 
care through which they seek assistance. Veterans were members of some of the highest performing military combat teams and they were asked to do the unimaginable and unthinkable under a considerable degree of physical and emotional distress. They accomplished their goals and they did this together. There is a lot that we can learn from Veterans, and we must work together to create and continue to develop these high-performing, integrated clinical treatment teams to serve Veterans. We must share our clinical expertise and join forces to provide care where patients feel comfortable and where providers are not limited by discipline or treatment setting. Leading-edge ideas and the dedication, commitment, and compassion of the medical providers and researchers will pave the way. This has to happen as a team, as soon as possible, and with the Veteran and his or her family at the forefront.

\section{ACKNOWLEDGMENTS}

Financial Contributions: The author has declared that no conflicting interests exist.

Funding/Support: This article was unfunded at the time of manuscript preparation.

\section{REFERENCES}

1. Icasualties [Internet]. Available from: http://icasualities.org

2. Gawande A. Casualties of war-military care for the wounded from Iraq and Afghanistan. N Engl J Med. 2004; 351(24):2471-75. [PMID:15590948] http://dx.doi.org/10.1056/NEJMp048317

3. Helmer DA, Chandler HK, Quigley KS, Blatt M, Teichman R, Lange G. Chronic widespread pain, mental health, and physical role function in OEF/OIF veterans. Pain Med. 2009;10(7):1174-82. [PMID:19818029] http://dx.doi.org/10.1111/j.1526-4637.2009.00723.x

4. Merskey H, Bogduk N, editors. Classification of chronic pain. IASP task force on taxonomy. Seattle (WA): IASP Press; 1994. p. 209-14.

5. Gatchel RJ. Psychological disorders and chronic pain: Cause and effect relationships. In: Gatchel RJ, Turk D, editors. Psychological approaches to pain management: A practitioner’s handbook. New York (NY): Guilford; 1996. p. 33-52.

6. Benedetto MC, Kerns RD, Rosenberg R. Health risk behaviors and healthcare utilization among veterans receiving primary medical care. J Clin Psychol Med Settings. 1998;5:441-47.

http://dx.doi.org/10.1023/A:1026258911757
7. Feuerstein M, Huang GD, Pransky G. Work style and work related upper extremity disorders. In: Gatchel RJ, Turk DC, editors. Psychosocial factors in pain. New York (NY): Guilford; 1999. p. 175-92.

8. Weisberg JN, Vaillancourt PD. Personality factors and disorders in chronic pain. Semin Clin Neuropsychiatry. 1999;4(3):155-66. [PMID:10498783]

9. Kessler RC, Sonnega A, Bromet E, Hughes M, Nelson CB. Posttraumatic stress disorder in the National Comorbidity Survey. Arch Gen Psychiatry. 1995;52(12):1048-60. [PMID:7492257] http://dx.doi.org/10.1001/archpsyc.1995.03950240066012

10. Norris FH. Epidemiology of trauma: frequency and impact of different potentially traumatic events on different demographic groups. J Consult Clin Psychol. 1992; 60(3):409-18. [PMID:1619095] http://dx.doi.org/10.1037/0022-006X.60.3.409

11. Resnick HS, Kilpatrick DG, Dansky BS, Saunders BE, Best CL. Prevalence of civilian trauma and posttraumatic stress disorder in a representative national sample of women. J Consult Clin Psychol. 1993;61(6):984-91. [PMID:8113499] http://dx.doi.org/10.1037/0022-006X.61.6.984

12. Dohrenwend BP, Turner JB, Turse NA, Adams BG, Koenen KC, Marshall R. The psychological risks of Vietnam for U.S. veterans: a revisit with new data and methods. Science. 2006;313(5789):979-82. [PMID:16917066] http://dx.doi.org/10.1126/science.1128944

13. Richardson LK, Frueh BC, Acierno R. Prevalence estimates of combat-related post-traumatic stress disorder: critical review. Aust N Z J Psychiatry. 2010;44(1):4-19. [PMID:20073563] http://dx.doi.org/10.3109/00048670903393597

14. Ford JD, Campbell KA, Storzbach D, Binder LM, Anger WK, Rohlman DS. Posttraumatic stress symptomatology is associated with unexplained illness attributed to Persian Gulf War military service. Psychosom Med. 2001;63(5): 842-49. [PMID:11573034]

15. Baker D, Mendenhall C, Simbartl L, Magan L, Steinberg J. Relationship between posttraumatic stress disorder and self-reported physical symptoms in Persian Gulf War veterans. Arch Intern Med. 1997;157(18):2076-78. [PMID:9382663] http://dx.doi.org/10.1001/archinte.1997.00440390062009

16. Beckham JC, Crawford AL, Feldman ME, Kirby AC, Hertzberg MA, Davidson JR, Moore SD. Chronic posttraumatic stress disorder and chronic pain in Vietnam combat veterans. J Psychosom Res. 1997;43(4):379-89. [PMID:9330237] http://dx.doi.org/10.1016/S0022-3999(97)00129-3 
17. White P, Faustman W. Coexisting physical conditions among inpatients with post-traumatic stress disorder. Mil Med. 1989;154(2):66-71. [PMID:2494581]

18. Jarvis C. "If he comes home nervous": US World War II neuropsychiatric casualties and post war masculinities. J Mens Stud. 2009;17(2):97-115.

http://dx.doi.org/10.3149/jms.1702.97

19. Lew HL, Otis JD, Tun C, Kerns RD, Clark ME, Cifu DX. Prevalence of chronic pain, posttraumatic stress disorder, and persistent postconcussive symptoms in OIF/OEF veterans: polytrauma clinical triad. J Rehabil Res Dev. 2009; 46(6):697-702. [PMID:20104399]

http://dx.doi.org/10.1682/JRRD.2009.01.0006

20. Wilson DR. Health consequences of childhood sexual abuse. Perspect Psychiatr Care. 2010;46(1):56-64.

[PMID:20051079]

http://dx.doi.org/10.1111/j.1744-6163.2009.00238.x

21. Wuest J, Ford-Gilboe M, Merritt-Gray M, Wilk P, Campbell JC, Lent B, Varcoe C, Smye V. Pathways of chronic pain in survivors of intimate partner violence. J Womens Health (Larchmt). 2010;19(9):1665-74.

[PMID:20718626]

http://dx.doi.org/10.1089/jwh.2009.1856

22. Public Health [Internet]. Washington (DC): Department of Veterans Affairs; 2012 [cited 2011 Apr]. Available from: http://www.publichealth.va.gov

23. Stuart JA, Murray KM, Ursano RJ, Wright KM. The Department of Defense's Persian Gulf War registry year 2000: an examination of veterans' health status. Mil Med. 2002;167(2):121-28. [PMID:11873533]

24. Murphy FM, Kang H, Dalager NA, Lee KY, Allen RE, Mather SH, Kizer KW. The health status of Gulf War veterans: lessons learned from the Department of Veterans Affairs Health Registry. Mil Med. 1999;164(5):327-31. [PMID:10332170]

25. Kang HK, Mahan CM, Lee KY, Magee CA, Murphy FM. Illnesses among United States veterans of the Gulf War: a population-based survey of 30,000 veterans. J Occup Environ Med. 2000;42(5):491-501. [PMID:10824302] http://dx.doi.org/10.1097/00043764-200005000-00006

26. Villano CL, Rosenblum A, Magura S, Fong C, Cleland C, Betzler TF. Prevalence and correlates of posttraumatic stress disorder and chronic severe pain in psychiatric outpatients. J Rehabil Res Dev. 2007;44(2):167-78.

[PMID:17551871]

http://dx.doi.org/10.1682/JRRD.2006.05.0052

27. Otis JD, Keane TM, Kerns RD. An examination of the relationship between chronic pain and post-traumatic stress disorder. J Rehabil Res Dev. 2003;40(5):397-405. [PMID:15080224] http://dx.doi.org/10.1682/JRRD.2003.09.0397
28. Gironda RJ, Clark ME, Massengale JP, Walker RL. Pain among veterans of Operations Enduring Freedom and Iraqi Freedom. Pain Med. 2006;7(4):339-43.

[PMID:16898945]

http://dx.doi.org/10.1111/j.1526-4637.2006.00146.x

29. Asmundson GJ, Katz J. Understanding the co-occurrence of anxiety disorders and chronic pain: state-of-the-art. Depress Anxiety. 2009;26(10):888-901. [PMID:19691031] http://dx.doi.org/10.1002/da.20600

30. Sharp TJ, Harvey AG. Chronic pain and posttraumatic stress disorder: mutual maintenance? Clin Psychol Rev. 2001; 21(6):857-77. [PMID:11497210] http://dx.doi.org/10.1016/S0272-7358(00)00071-4

31. Vlaeyen JW, Linton SJ. Fear-avoidance and its consequences in chronic musculoskeletal pain: a state of the art. Pain. 2000;85(3):317-32. [PMID:10781906] http://dx.doi.org/10.1016/S0304-3959(99)00242-0

32. Norton PJ, Asmundson GJ. Amending the fear-avoidance model of chronic pain: What is the role of physiological arousal? Behav Therapy. 2003;34:17-30. http://dx.doi.org/10.1016/S0005-7894(03)80019-9

33. Keane TM, Barlow DH. Posttraumatic stress disorder. In: Anxiety and its disorders. New York (NY): Guilford Press; 2002. p. 418-53.

34. Barlow DH. Unraveling the mysteries of anxiety and its disorders from the perspective of emotion theory. Am Psychol. 2000;55(11):1247-63. [PMID:11280938] http://dx.doi.org/10.1037/0003-066X.55.11.1247

35. Asmundson GJ, Coons MJ, Taylor S, Katz J. PTSD and the experience of pain: research and clinical implications of shared vulnerability and mutual maintenance models. Can J Psychiatry. 2002;47(10):930-37.

[PMID:12553128]

36. McLean SA, Clauw DJ, Abelson JL, Liberzon I. The development of persistent pain and psychological morbidity after motor vehicle collision: integrating the potential role of stress response systems into a biopsychosocial model. Psychosom Med. 2005;67(5):783-90. [PMID:16204439]

37. McLean SA, Clauw DJ. Predicting chronic symptoms after an acute "stressor"-lessons learned from 3 medical conditions. Med Hypotheses. 2004;63(4):653-58.

[PMID:15325010] http://dx.doi.org/10.1016/j.mehy.2004.03.022

38. Fukunishi I. Relationship of cosmetic disfigurement to the severity of posttraumatic stress disorder in burn injury or digital amputation. Psychother Psychosom. 1999;68(2): 82-86. [PMID:10026459] http://dx.doi.org/10.1159/000012317

39. Kruzel JJ. Army moves aggressively to treat blast-related injuries. Mil Med. 2008;173:5-6. 
40. Cooper DB, Kennedy JE, Cullen MA, Critchfield E, Amador RR, Bowles AO. Association between combat stress and post-concussive symptom reporting in OEF/ OIF service members with mild traumatic brain injuries. Brain Inj. 2011;25(1):1-7. [PMID:21117916] http://dx.doi.org/10.3109/02699052.2010.531692

41. Kennedy JE, Jaffee MS, Leskin GA, Stokes JW, Leal FO, Fitzpatrick PJ. Posttraumatic stress disorder and posttraumatic stress disorder-like symptoms and mild traumatic brain injury. J Rehabil Res Dev. 2007;44(7):895-920.

[PMID:18075948]

http://dx.doi.org/10.1682/JRRD.2006.12.0166

42. Wallace D. Improvised explosive devices and traumatic brain injury: the military experience in Iraq and Afghanistan. Australas Psychiatry. 2009;17(3):218-24.

[PMID:19404818]

http://dx.doi.org/10.1080/10398560902878679

43. Abenhaim L, Dab W, Salmi LR. Study of civilian victims of terrorist attacks (France 1982-1987). J Clin Epidemiol. 1992;45(2):103-9. [PMID:1573426] http://dx.doi.org/10.1016/0895-4356(92)90002-5

44. Verger P, Dab W, Lamping DL, Loze JY, DeschaseauxVoinet C, Abenhaim L, Rouillon F. The psychological impact of terrorism: an epidemiologic study of posttraumatic stress disorder and associated factors in victims of the 1995-1996 bombings in France. Am J Psychiatry. 2004;161(8):1384-89. [PMID:15285963] http://dx.doi.org/10.1176/appi.ajp.161.8.1384

45. Gillespie K, Duffy M, Hackmann A, Clark DM. Community based cognitive therapy in the treatment of posttraumatic stress disorder following the Omagh bomb. Behav Res Ther. 2002;40(4):345-57. [PMID:12002894] http://dx.doi.org/10.1016/S0005-7967(02)00004-9

46. Clark ME, Walker RL, Gironda RJ, Scholten JD. Comparison of pain and emotional symptoms in soldiers with polytrauma: unique aspects of blast exposure. Pain Med. 2009; 10(3):447-55. [PMID:19416436] http://dx.doi.org/10.1111/j.1526-4637.2009.00590.x

47. Bair MJ, Robinson RL, Katon W, Kroenke K. Depression and pain comorbidity: a literature review. Arch Intern Med. 2003;163(20):2433-45. [PMID:14609780] http://dx.doi.org/10.1001/archinte.163.20.2433

48. Poundja J, Fikretoglu D, Brunet A. The co-occurrence of posttraumatic stress disorder symptoms and pain: is depression a mediator? J Trauma Stress. 2006;19(5):747-51. [PMID:17075919] http://dx.doi.org/10.1002/jts.20151

49. Banks SM, Kerns RD. Explaining high rates of depression in chronic pain: a diathesis-stress framework. Psychol Bull. 1996;119(1):95-110. http://dx.doi.org/10.1037/0033-2909.119.1.95
50. Trafton JA, Oliva EM, Horst DA, Minkel JD, Humphreys $\mathrm{K}$. Treatment needs associated with pain in substance use disorder patients: implications for concurrent treatment. Drug Alcohol Depend. 2004;73(1):23-31. [PMID:14687956] http://dx.doi.org/10.1016/j.drugalcdep.2003.08.007

51. Leeies M, Pagura J, Sareen J, Bolton JM. The use of alcohol and drugs to self-medicate symptoms of posttraumatic stress disorder. Depress Anxiety. 2010;27(8):731-36. [PMID:20186981]

52. McFall M, Atkins DC, Yoshimoto D, Thompson CE, Kanter E, Malte CA, Saxon AJ. Integrating tobacco cessation treatment into mental health care for patients with posttraumatic stress disorder. Am J Addict. 2006;15(5): 336-44. [PMID:16966189] http://dx.doi.org/10.1080/10550490600859892

53. Department of Veterans Affairs. VA/DoD clinical practice guidelines: Management of substance use disorder (SUD) (2009) [Internet]. Department of Veterans Affairs; 2009. Available from: http://www.healthquality.va.gov/ Substance Use Disorder SUD.asp

54. Astin JA, Forys K. Psychosocial determinants of health and illness: integrating mind, body, and spirit. Adv Mind Body Med. 2004;20(4):14-21. [PMID:15689022]

55. Gross CR, Kreitzer MJ, Russas V, Treesak C, Frazier PA, Hertz MI. Mindfulness meditation to reduce symptoms after organ transplant: a pilot study. Adv Mind Body Med. 2004;20(2):20-29. [PMID:15356953]

56. Meili T, Kabat-Zinn J. The power of the human heart: a story of trauma and recovery and its implications for rehabilitation and healing. Adv Mind Body Med. 2004;20(1): 6-16. [PMID:15068105]

57. Wald J, Taylor S, Fedoroff IC. The challenge of treating PTSD in the context of chronic pain. In: Taylor S, editor. Advances in the treatment of posttraumatic stress disorder. New York (NY): Springer; 2004. p. 197-222.

58. Morley S, Eccleston C, Williams A. Systematic review and meta-analysis of randomized controlled trials of cognitive behaviour therapy and behaviour therapy for chronic pain in adults, excluding headache. Pain. 1999; 80(1-2):1-13. [PMID:10204712] http://dx.doi.org/10.1016/S0304-3959(98)00255-3

59. Foa EB, Keane TM, Friedman MJ. Effective treatments for PTSD: Practice guidelines from the International Society for Traumatic Stress Studies. New York (NY): Guilford Press; 2000.

60. Dahl S, Dahl CI, Sandvik L, Hauff E. [Chronic pain in traumatized refugees]. Tidsskr Nor Laegeforen. 2006; 126(5):608-10. Norwegian. [PMID:16505872]

61. Claassen D, Ascoli M, Berhe T, Priebe S. Research on mental disorders and their care in immigrant populations: 
a review of publications from Germany, Italy and the UK. Eur Psychiatry. 2005;20(8):540-49. [PMID:15963698]

http://dx.doi.org/10.1016/j.eurpsy.2005.02.010

62. Management of Post-Traumatic Stress Working Group [Internet]. VA/DOD clinical practice guideline for management of post-traumatic stress. Washington (DC): Department of Veterans Affairs; Department of Defense; 2010. Available from:

http://www.healthquality.va.gov/ptsd/ptsd full.pdf

63. Rush AJ, Trivedi MH, Stewart JW, Nierenberg AA, Fava M, Kurian BT, Warden D, Morris DW, Luther JF, Husain MM, Cook IA, Shelton RC, Lesser IM, Kornstein SG, Wisniewski SR. Combining medications to enhance depression outcomes (CO-MED): acute and long term outcomes of a single-blind randomized study. Am J Psychiatry. 2011; 168(7):689-701. [PMID:21536692]

http://dx.doi.org/10.1176/appi.ajp.2011.10111645

64. Dawson ME, Schell AM, Filion DL. The electrodermal system. In: Cacioppo JT, Tassinary LG, Berntson GG, editors. Handbook of psychophysiology. 3rd ed. New York (NY): Cambridge University Press; 2007.

65. Department of Veterans Affairs. VA/DoD clinical practice guidelines: Management of opioid therapy (OT) for chronic pain (2010) [Internet]. Washington (DC): Department of Veterans Affairs; 2010. Available from:

http://www.healthquality.va.gov/

Chronic Opioid Therapy COT.asp

66. Butler SF, Budman SH, Fernandez KC, Jamison RN. Validation of a screener and opioid assessment measure for patients with chronic pain. Pain. 2004;112(1-2):65-75.

[PMID:15494186]

http://dx.doi.org/10.1016/j.pain.2004.07.026

67. Butler SF, Budman SH, Fernandez KC, Fanciullo GJ, Jamison RN. Cross validation of a screener to predict opioid misuse in chronic pain patients (SOAPP-R). J Addict Med. 2009;3(2):66-73. [PMID:20161199] http://dx.doi.org/10.1097/ADM.0b013e31818e41da

68. Moore TM, Jones T, Browder JH, Daffron S, Passik SD. A comparison of common screening methods for predicting aberrant drug-related behavior among patients receiving opioids for chronic pain management. Pain Med. 2009; 10(8):1426-33. [PMID:20021601]

http://dx.doi.org/10.1111/j.1526-4637.2009.00743.x

69. Portenoy RK. Opioid therapy for chronic nonmalignant pain: a review of the critical issues. J Pain Symptom Manage. 1996;11(4):203-17. [PMID:8869456] http://dx.doi.org/10.1016/0885-3924(95)00187-5

70. Nicholson B, Passik SD. Management of chronic noncancer pain in the primary care setting. South Med J. 2007; 100(10):1028-36. [PMID:17943050] http://dx.doi.org/10.1097/SMJ.0b013e3180f626ff
71. Bohnert AS, Ilgen MA, Ignacio RV, McCarthy JF, Valenstein M, Blow FC. Risk of death from accidental overdose associated with psychiatric and substance use disorders. Am J Psychiatry. 2012;169(1):64-70. [PMID:21955932]

72. Veilleux JC, Colvin PJ, Anderson J, York C, Heinz AJ. A review of opioid dependence treatment: pharmacological and psychosocial interventions to treat opioid addiction. Clin Psychol Rev. 2010;30(2):155-66. [PMID:19926374] http://dx.doi.org/10.1016/j.cpr.2009.10.006

73. Hayes SC, Wilson KG, Gifford EV, Bissett R, Piasecki M, Batten SV, Byrd M, Gregg J. A preliminary trial of twelvestep facilitation and acceptance and commitment therapy with polysubstance-abusing methadone-maintained opiate addicts. Behav Ther. 2004;35:667-88. http://dx.doi.org/10.1016/S0005-7894(04)80014-5

74. McCracken LM, Vowles KE, Gauntlett-Gilbert J. A prospective investigation of acceptance and control-oriented coping with chronic pain. J Behav Med. 2007;30(4):339-49. [PMID:17447131] http://dx.doi.org/10.1007/s10865-007-9104-9

75. Vowles KE, McNeil DW, Gross RT, McDaniel ML, Mouse A, Bates M, Gallimore P, McCall C. Effects of pain acceptance and pain control strategies on physical impairment in individuals with chronic low back pain. Behav Ther. 2007;38(4):412-25. [PMID:18021955] http://dx.doi.org/10.1016/j.beth.2007.02.001

76. Vowles KE, Wetherell JL, Sorell JT. Targeting acceptance, mindfulness, and values-based action in chronic pain: findings of two preliminary trials of an outpatient groupbased intervention. Cogn Behav Pract. 2009;16:49-58. http://dx.doi.org/10.1016/j.cbpra.2008.08.001

77. Dodrill CL, Helmer DA, Kosten TR. Prescription pain medication dependence. Am J Psychiatry. 2011;168(5): 466-71. [PMID:21536702] http://dx.doi.org/10.1176/appi.ajp.2010.10020260

78. Savage SR, Joranson DE, Covington EC, Schnoll SH, Heit HA, Gilson AM. Definitions related to the medical use of opioids: evolution towards universal agreement. J Pain Symptom Manage. 2003;26(1):655-67. [PMID:12850648] http://dx.doi.org/10.1016/S0885-3924(03)00219-7

79. Kowal N. What is the issue?: pseudoaddiction or undertreatment of pain. Nurs Econ. 1999;17(6):348-49. [PMID:10711190]

80. Chou R, Qaseem A, Snow V, Casey D, Cross JT Jr, Shekelle P, Owens DK; Clinical Efficacy Assessment Subcommittee of the American College of Physicians; American College of Physicians; American Pain Society Low Back Pain Guidelines Panel. Diagnosis and treatment of low back pain: a joint clinical practice guideline from the American College of Physicians and the American Pain Society. Ann Intern Med. 2007;147(7):478-91. [PMID:17909209] 
81. Peterlin BL, Tietjen G, Meng S, Lidicker J, Bigal M. Posttraumatic stress disorder in episodic and chronic migraine. Headache. 2008;48(4):517-22. [PMID:18377377] http://dx.doi.org/10.1111/j.1526-4610.2008.00917.x

82. Teper SJ, Mays M. Up-to-date pharmacologic options for managing headache pain [Internet]. New York (NY): Medscape Education; 2008. Available from: http://www.medscape.org/viewarticle/582294_1

83. Shipherd JC, Beck JG, Hamblen JL, Lackner JM, Freeman JB. A preliminary examination of treatment for posttraumatic stress disorder in chronic pain patients: a case study. J Trauma Stress. 2003;16(5):451-57. [PMID:14584629] http://dx.doi.org/10.1023/A:1025754310462

84. Dodick DW, Turkel CC, DeGryse RE, Aurora SK, Silberstein SD, Lipton RB, Diener HC, Brin MF; PREEMPT Chronic Migraine Study Group. OnabotulinumtoxinA for treatment of chronic migraine: pooled results from the double-blind, randomized, placebo-controlled phases of the PREEMPT clinical program. Headache. 2010;50(6): 921-36. [PMID:20487038]

http://dx.doi.org/10.1111/j.1526-4610.2010.01678.x

85. Baron R, Tölle TR. Assessment and diagnosis of neuropathic pain. Curr Opin Support Palliat Care. 2008;2(1):1-8. [PMID:18685386] http://dx.doi.org/10.1097/SPC.0b013e3282f57da5

86. Haanpää ML, Gourlay GK, Kent JL, Miaskowski C, Raja SN, Schmader KE, Wells CD. Treatment considerations for patients with neuropathic pain and other medical comorbidities. Mayo Clin Proc. 2010;85(3 Suppl):S15-25. [PMID:20194144] http://dx.doi.org/10.4065/mcp.2009.0645

87. Kuritzky L. Managing diabetic peripheral neuropathic pain in primary care. J Fam Pract. 2010;59(5 Suppl):S15-22. [PMID:20544053]

88. Attal N, Cruccu G, Baron R, Haanpää M, Hansson P, Jensen TS, Nurmikko T; European Federation of Neurological Societies. EFNS guidelines on the pharmacological treatment of neuropathic pain: 2010 revision. Eur J Neurol. 2010;17(9):1113-e88. [PMID:20402746] http://dx.doi.org/10.1111/j.1468-1331.2010.02999.x

89. Vreeland B. Bridging the gap between mental and physical health: a multidisciplinary approach. J Clin Psychiatry. 2007;68(4 Suppl 4):26-33. [PMID:17539697]

90. Marder SR, Essock SM, Miller AL, Buchanan RW, Casey DE, Davis JM, Kane JM, Lieberman JA, Schooler NR, Covell N, Stroup S, Weissman EM, Wirshing DA, Hall CS, Pogach L, Pi-Sunyer X, Bigger JT Jr, Friedman A, Kleinberg D, Yevich SJ, Davis B, Shon S. Physical health monitoring of patients with schizophrenia. Am J Psychiatry. 2004;161(8):1334-49. [PMID:15285957] http://dx.doi.org/10.1176/appi.ajp.161.8.1334
91. Dixon LB, Adler DA, Berlant JL, Dulit RA, Goldman B, Hackman AL, Oslin DW, Siris SG, Sonis WA, Valenstein M. Psychiatrists and primary caring: what are our boundaries of responsibility? Psychiatr Serv. 2007;58(5):600-602. [PMID:17463337] http://dx.doi.org/10.1176/appi.ps.58.5.600

92. Smeeding SJ, Bradshaw DH, Kumpfer K, Trevithick S, Stoddard GJ. Outcome evaluation of the Veterans Affairs Salt Lake City Integrative Health Clinic for chronic pain and stress-related depression, anxiety, and post-traumatic stress disorder. J Altern Complement Med. 2010;16(8): 823-35. [PMID:20649442] http://dx.doi.org/10.1089/acm.2009.0510

93. Foa EB, Davidson JR, Frances A. Treatment of traumatic stress disorder. J Clin Psychiatry. 1999;60(16):60-66.

94. Monson CM, Schnurr PP, Resick PA, Friedman MJ, Young$\mathrm{Xu}$ Y, Stevens SP. Cognitive processing therapy for veterans with military-related posttraumatic stress disorder. J Consult Clin Psychol. 2006;74(5):898-907. [PMID:17032094] http://dx.doi.org/10.1037/0022-006X.74.5.898

95. Seal KH, Maguen S, Cohen B, Gima KS, Metzler TJ, Ren L, Bertenthal D, Marmar CR. VA mental health services utilization in Iraq and Afghanistan veterans in the first year of receiving new mental health diagnoses. J Trauma Stress. 2010;23(1):5-16. [PMID:20146392]

96. Seal KH, Metzler TJ, Gima KS, Bertenthal D, Maguen S, Marmar CR. Trends and risk factors for mental health diagnoses among Iraq and Afghanistan veterans using Department of Veterans Affairs health care, 2002-2008. Am J Public Health. 2009;99(9):1651-58. [PMID:19608954] http://dx.doi.org/10.2105/AJPH.2008.150284

97. Hoge CW, Castro CA, Messer SC, McGurk D, Cotting DI, Koffman RL. Combat duty in Iraq and Afghanistan, mental health problems, and barriers to care. $\mathrm{N}$ Engl J Med. 2004;351(1):13-22. [PMID:15229303] http://dx.doi.org/10.1056/NEJMoa040603

98. Engel CC, Oxman T, Yamamoto C, Gould D, Barry S, Stewart P, Kroenke K, Williams JW Jr, Dietrich AJ. RESPECTMil: feasibility of a systems-level collaborative care approach to depression and post-traumatic stress disorder in military primary care. Mil Med. 2008;173(10):935-40. [PMID:19160608]

99. Wagner A, Zatzick D, Ghesquiere A, Jurkovich G. Behavioral activation as an early intervention for posttraumatic stress disorder and depression among physically injured trauma survivors. Cogn Behav Pract. 2007;14:341-49. http://dx.doi.org/10.1016/j.cbpra.2006.05.002

100. Jacobson NS, Dobson KS, Truax PA, Addis ME, Koerner K, Gollan JK, Gortner E, Prince SE. A component analysis of cognitive-behavioral treatment for depression. J Consult 
JRRD, Volume 49, Number 5, 2012

Clin Psychol. 1996;64(2):295-304. [PMID:8871414]

http://dx.doi.org/10.1037/0022-006X.64.2.295

101. Zatzick DF, Roy-Byrne P, Russo J, Rivara FP, Droesch R, Wagner A, Dunn C, Jurkovich G, Uehara E, Katon W. A randomized effectiveness trial of stepped collaborative care for acutely injured trauma survivors. Arch Gen Psychiatry. 2004;61(5):498-506. [PMID:15123495] http://dx.doi.org/10.1001/archpsyc.61.5.498

102. Jakupcak M, Wagner A, Paulson A, Varra A, McFall M. Behavioral activation as a primary care-based treatment for PTSD and depression among returning veterans. J Trauma Stress. 2010;23(4):491-95. [PMID:20623596] http://dx.doi.org/10.1002/jts.20543

103. Otis JD, Keane TM, Kerns RD, Monson C, Scioli E. The development of an integrated treatment for veterans with comorbid chronic pain and posttraumatic stress disorder.
Pain Med. 2009;10(7):1300-1311. [PMID:19818040]

http://dx.doi.org/10.1111/j.1526-4637.2009.00715.x

Submitted for publication September 2, 2011. Accepted in revised form January 5, 2012.

This article and all supplementary material should be cited as follows:

Gibson CA. Review of posttraumatic stress disorder and chronic pain: The path to integrated care. J Rehabil Res Dev. 2012;49(5):753-76.

http://dx.doi.org/10.1682/JRRD.2011.09.0158

ALL SUBUSSIONS SCREENED BY $\checkmark$ iThenticate*

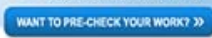

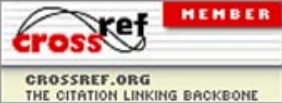

